\title{
The role of indigenous phlebotomine sandflies and mammals in the spreading of leishmaniasis agents in the Mediterranean region
}

M Antoniou ${ }^{1}$, M Gramiccia ${ }^{2}$, R Molina 3 , V Dvorak (vidvorak@natur.cuni.cz) ${ }^{4}$, P Volf 4

1. Laboratory of Clinical Bacteriology Parasitology Zoonoses and Geographical Medicine, Faculty of Medicine, University of Crete, Iraklion, Greece

2. Unit of Vector-borne Diseases and International Health, MIPI Department, Istituto Superiore di Sanità, Rome, Italy

3. Medical Entomology Unit, Servicio de Parasitología, Centro Nacional de Microbiología, Instituto de Salud Carlos III, Majadahonda, Madrid, Spain

4. Department of Parasitology, Faculty of Science, Charles University, Prague, Czech Republic

Citation style for this article:

Antoniou M, Gramiccia M, Molina R, Dvorak V, Volf $\mathrm{P}$. The role of indigenous phlebotomine sandflies and mammals in the spreading of leishmaniasis agents in the Mediterranean region. Euro Surveill. 2013;18(30):pii=20540. Available online: http://www.eurosurveillance.org/ViewArticle.aspx?Articleld=20540

An updated view of the establishment and spread of the leishmaniases in Europe is presented, mostly with respect to newly emerging and re-emerging foci and the incrimination of neglected as well as new reservoir hosts. At the same time, a concept of specific versus permissive vectors reassesses the potential role of various sandfly species in Leishmania transmission and considers the risk of introduction of exotic Leishmania species in Europe. The leishmaniases are dynamic diseases and the circumstances of transmission are continually changing in relation to environmental, demographic and human behavioural factors. Changes in the habitat of the natural hosts and vectors, immunosuppressive conditions (like infection with human immunodeficiency virus (HIV) or organ transplantation-associated therapies in humans) and the consequences of war, all contribute to the transformation of the epidemiology of leishmaniasis. Such changes should be considered when studying the spread of the disease throughout Europe for targeted control measures to safeguard public health.

\section{Endemic burden of human \\ leishmaniases in Europe}

The leishmaniases are vector-borne diseases that have been endemic in southern Europe for centuries. They are transmitted by the bite of phlebotomine sandflies belonging to the genus Phlebotomus and most often exhibit one of two endemic clinical entities in humans, zoonotic visceral leishmaniasis (VL) and sporadic cutaneous leishmaniasis (CL). Four Leishmania species occur in the Mediterranean basin: L. infantum, the most frequent species, causing both $\mathrm{VL}$ and $\mathrm{CL}$; L. major, occurring in North Africa and the Middle East, causing CL; L. tropica, found in Greece, Turkey, the Middle East and North Africa, causing CL; L. donovani, recently introduced in Cyprus, causing both VL and CL. These species are able to spread in new geographical areas where suitable sandfly vectors are present in sufficient numbers and under favourable ecological conditions. The risk is greater when the anthroponotic species, $L$. tropica and L. donovani, are involved, because reservoir hosts other than human are not required to complete the transmission cycle. It is widely accepted that the leishmaniases are dynamic diseases. As the conditions of transmission change (environmental, demographic, human behaviour and health), epidemiological studies and control measures to safeguard public health should be adapted for the application of successful monitoring measures.

The incidence of zoonotic VL caused by L. infantum in humans is relatively low (0.02-0.49/100,000 in the general population) with an average of about 700 clinical cases reported each year in southern Europe $[1,2]$. However, outbreaks or recrudescence may occur periodically in foci like the new focus in Spain where incidences increased up to 56 per 100,000 [3]. Incidence rates of sporadic $\mathrm{CL}$, although generally accepted as high (in the range of one to a few 100), are not available because of poor notification.

Visceral leishmaniasis constitutes a problem in immunocompromised individuals. Starting from the early 1990s, the impact of co-infections with Leishmania and human immunodeficiency virus (HIV) was recognised as an alarming problem by international health authorities. Cases were reported from 35 countries worldwide, mostly in south-western Europe (France, Italy, Portugal and Spain), showing an association between the HIV pandemic and the zoonotic entity of VL caused by $L$. infantum. The cumulative number of co-infections recorded by a surveillance network from the World Health Organization (WHO) and UNAIDS was 692 by early 1995,965 by 1998 , and 1911 by early 2001. Spanish cases accounted for $57 \%$ of all co-infections worldwide, probably reflecting a relatively large area of Leishmania/HIV sympatry in Spain. The demonstration 
of unusual modes of anthroponotic transmission (i.e. by syringe exchange) and the high rate of relapses following anti-leishmanial treatments, were alarming features indicating a trend toward an even higher incidence. By the end of the 1990s, however, several reports indicated that the $L$. infantum/HIV epidemic peak declined due to the introduction of the highly active antiretroviral therapy (HAART) which not only reduced the number of new cases of co-infection, but also the rate of $\mathrm{VL}$ relapses in individuals with restored immunological parameters (i.e. with a CD4+ count $200 /$ $\mu \mathrm{L})$. Currently, very few HIV-infected individuals with clinical VL are recorded annually in southern Europe, mainly in patients with acquired immunodeficiency syndrome (AIDS) who are unresponsive to HAART. Other countries, such as Germany, Greece, Switzerland and the United Kingdom currently report sporadic imported cases [4].

The spread of leishmaniases may be enhanced by globalisation, climatic change and other conditions which allow the parasite and its vectors to spread in space and time. Studies to foresee the effect of such changes have been undertaken by the EDENext EU FP7 (www. edenext.eu) project in order to safeguard unaffected areas by preventing the introduction, establishment and spread of the Leishmania pathogen and its vectors. Data on the disease and its spatial distribution in Europe and the Mediterranean basin were composed and made accessible online to researchers and public health officials (www.edenextdata.com) so that knowledge-based decisions could be made for monitoring the disease.

Increasing evidence suggests that elevated rates of asymptomatic $L$. infantum carriers are an indicator of the intense Leishmania circulation in southern Europe. Infection prevalences, as high as $10-47 \%$ in particular age groups, were recorded in healthy individuals from endemic foci of France, Greece, Italy and Spain by traditional and molecular methods [5]. On the other hand, $\mathrm{CL}$ cases, autochthonous or imported, may not seek treatment, especially in cases with mild clinical forms or older people and illegal immigrants. When the disease is introduced in new areas, physicians who are not familiar with the problem often do not consider $\mathrm{CL}$ in their differential diagnosis, and hence appropriate treatment is not given, allowing parasite circulation.

\section{Literature search strategy}

Scientific literature for the purposes of this review was searched in May 2012 by all participating co-authors, sourcing the PubMed and Scopus databases. An electronic search was conducted among articles from 1970 until recently, as well as a few relevant older references, cross-referencing the following combination of keywords: 'leishmaniasis' and 'Phlebotomus' and 'emergence' and 'reservoirs'. Titles relevant to the scope of this review (an updated view of the establishment and spread of the leishmaniases in Europe with respect to newly emerging and re-emerging foci and the incrimination of neglected and new reservoir hosts) were obtained in full text and selected for inclusion. Unpublished data and titles from non-peer-reviewed literature were not considered.

\section{Sandfly vectors}

The vectorial status of phlebotomine sandfly vectors of Leishmania in Europe and the Mediterranean area was recently reviewed $[6,7]$ and new species have recently been incriminated $[8,9]$. Nine proven, or potential, vector species (Phlebotomus ariasi, P. perniciosus, $P$. perfiliewi, $P$. neglectus, $P$. tobbi, $P$. kandelaki, $P$. balcanicus, $P$. papatasi and $P$. sergenti) are indigenous in Europe. In addition, species of questionable taxonomic status ( $P$. similis, $P$. syriacus) or of possible but unproven vectorial capacity ( $P$. mascittii) should be further studied. Traditionally, the limited number of known vectors was explained by the inability of some sandfly species to support the development of infective stages in their gut or because of unidentified ecological contact with reservoir hosts [6]. However, experimental infections, under laboratory conditions, revealed that only two tested sandfly species, $P$. papatasi and $P$. sergenti, are 'specific vectors'; they allow only the maturation of a single Leishmania species they transmit in nature (L. major and L. tropica, respectively) and do not support development of other Leishmania species [10-13]. Nonetheless, most sandfly species tested to date support development of multiple Leishmania spp. allowing them to mature in their midguts, thus falling into a category of the permissive vectors [9]. These species are members of the Larroussius and Adlerius subgenera, namely $P$. perniciosus, $P$. arabicus and $P$. halepensis. Although in nature, $P$. perniciosus is the proven vector of $L$. infantum in the western Mediterranean, $P$. arabicus the proven vector of L. tropica in Israel and $P$. halepensis the suspected vector of $L$. infantum in the Caucasus region, all three species supported full development of $L$. major and L. tropica under experimental conditions [14-16].

The broad vectorial competence of permissive sandfly species may have important epidemiological consequences and should be taken into account while estimating the risk of new leishmaniasis foci. The most important example is the introduction of $L$. infantum (syn. L. chagasi) from the Iberian Peninsula to Latin America, where it adapted to the local permissive sandfly Lutzomyia longipalpis [9]. Similarly, we can speculate that L. tropica could be transmitted by permissive vectors in the Mediterranean area, although $P$. sergenti was for a long time considered to be its sole vector. The vectorial capacity of $P$. similis, a sister species of $P$. sergenti, which is widely distributed in the north-eastern Mediterranean, is yet to be tested. $P$. arabicus, a proven vector in a CL focus in northern Israel [14], demonstrated a clear potential of permissivity to transmit the parasite.

While transcontinental import of new vectors to Europe by human activities appears improbable, due to the 
fragile nature of sandflies in comparison to the rather robust invasive mosquito species, a shift of sandfly occurrence to northern areas of Europe, traditionally regarded as Leishmania-free, was recently well documented. In northern Italy, an increase in the density and geographical expansion of the Leishmania vectors $P$. perniciosus and $P$. neglectus was observed in 2003 and 2004 compared with the situation described in the 1960 s and 1970s; this enabled the establishment and transmission of the parasite in the northern part of the country previously regarded as non-endemic [17]. In a similar manner, an increase in the incidence and distribution of canine leishmaniasis (CanL) was reported in 2007 from a new VL focus in southern France, a region outside the traditional endemic area of this disease. As no major changes in land use were observed, it was postulated that the increased CanL transmission could be attributed to vector dispersion ( $P$. perniciosus and $P$. ariasi) due to an increase in the mean summer temperature during the two decades preceding the reported increase, a possible effect of global climate change [18]. A similar situation was described in Spain where the current distribution was compared to the predicted spreading of sandfly vectors based on expected climate changes [19]. In Germany, the detection of leishmaniasis cases in humans and animals (dogs, cats, horses) that had never travelled outside the country, has led to the hypothesis of a recent establishment of autochthonous transmission [20], suggesting a northward expansion of $L$. infantum, although entomological surveys have so far not provided solid evidence for the presence of competent vector species in Germany.

\section{Reservoirs}

Dogs, which may suffer from severe disease (CanL), are the primary domestic reservoir hosts of zoonotic VL caused by $L$. infantum. Canine infections are widespread in southern Europe, representing both a public health threat and a veterinary problem. Infections in cats and horses have also been reported in areas where CanL is present, and cats may suffer from feline leishmaniasis syndrome, which is less severe compared to CanL [21]. In Europe, a number of other indigenous mammal species have been found infected by L. infantum, including Mus spretus (Algerian mouse), Apodemus sylvaticus (European wood mouse), Rattus rattus (black rat), Rattus norvegicus (brown rat), Meles meles (European badger), Martes martes (European pine marten), Mustela nivalis (weasel), Geneta geneta (common genet) and Vulpes vulpes (red fox) [6,21]. In addition to domestic dogs, the ability to transmit infection has been confirmed by xenodiagnosis in black rats and domestic cats [22], suggesting that they may represent a secondary reservoir host for $L$. infantum. The important question is: can any of these species serve as reservoir host, and can they participate in the establishment and spread of the parasite in new foci?

Zoonotic CL, caused by L. major, is not considered a threat for Europe, not even a very low risk, since its natural reservoir hosts, gerbils of the genera
Rhombomys, Psammomys and Meriones, are not found in European countries [6]. However, the recent finding that voles of the species Microtus guentheri, a common rodent in Balkan countries, were infected by L. major in Israel [5], has challenged this assumption. In contrast, CL caused by L. tropica is universally believed to be anthroponotic because it is prevalent in urban settings. However, dogs have been reported as possible reservoirs or accidental hosts of $L$. tropica in some countries [21]. In a broader geographical context of the Mediterranean region, several zoonotic foci have been described, with rock hyraxes (Procavia capensis) as reservoirs in Israel [7,14] and Ctenodactylus gundi rodents found infected and probably serving as reservoirs in the area of Maghreb [23]. These two examples from neighbouring areas to Europe illustrate that the traditional terms used for the diseases caused by $L$. tropica and L. major, 'anthroponotic CL' and 'zoonotic CL', respectively, may not be fully appropriate.

\section{Spread of endemic L. infantum and the risk of introduction of non- endemic Leishmania species}

Being previously confined to coastal Mediterranean biotopes, autochthonous leishmaniasis caused by L. infantum does not appear to be limited to these habitats anymore, suggesting an expansion towards new biotopes at northern latitudes and higher altitudes. During the period from 2002 to 2009, the northward spread of CanL was monitored in northern Italy, in newly endemic regions, with mean seroprevalences increasing from 1.8 to $4.7 \%$, and reported human VL and $C L$ cases [17]. In a region of the French Pyrenees, outside the traditional area endemic for leishmaniasis, CanL seroprevalence rates increased 10 -fold over a period of 13 years between 1994 and 2007 [18]. In south-eastern Spain, a progressive increase in CanL seroprevalence rates was reported at elevated altitudes in the Alpujarras region, climbing from $9.2 \%$ in 1984 to $20.1 \%$ in 2006 [24]. Furthermore, a new CanL focus was recently detected in a Pyrenean area of north-western Catalonia [25].

It transpires, from both published and unpublished information that leishmaniasis cases due to Leishmania species that are not indigenous to Europe, are indeed frequent $[6,21]$, occurring in migrants, visiting friends and relatives, or European citizens travelling to endemic countries outside Europe for tourism or work. Some $100 \mathrm{VL}, 400 \mathrm{CL}$ and $700 \mathrm{CanL}$ imported cases have been diagnosed and published from traditionally non-endemic countries of Europe north of the regions with natural occurrence of leishmaniases (Germany, the Netherlands and the United Kingdom). Information about non-indigenous Leishmania importation in endemic areas of southern Europe is scarce because it is difficult to discriminate between autochthonous and non-autochthonous cases that share similar clinical aspects. For example in Italy, during 2011 and 2012, about 20 cases (16 of them immunocompetent CL patients) from four New World and 10 non-European 
Human leishmaniasis outbreak of Fuenlabrada, Spain, 2009-2012 (n=449)

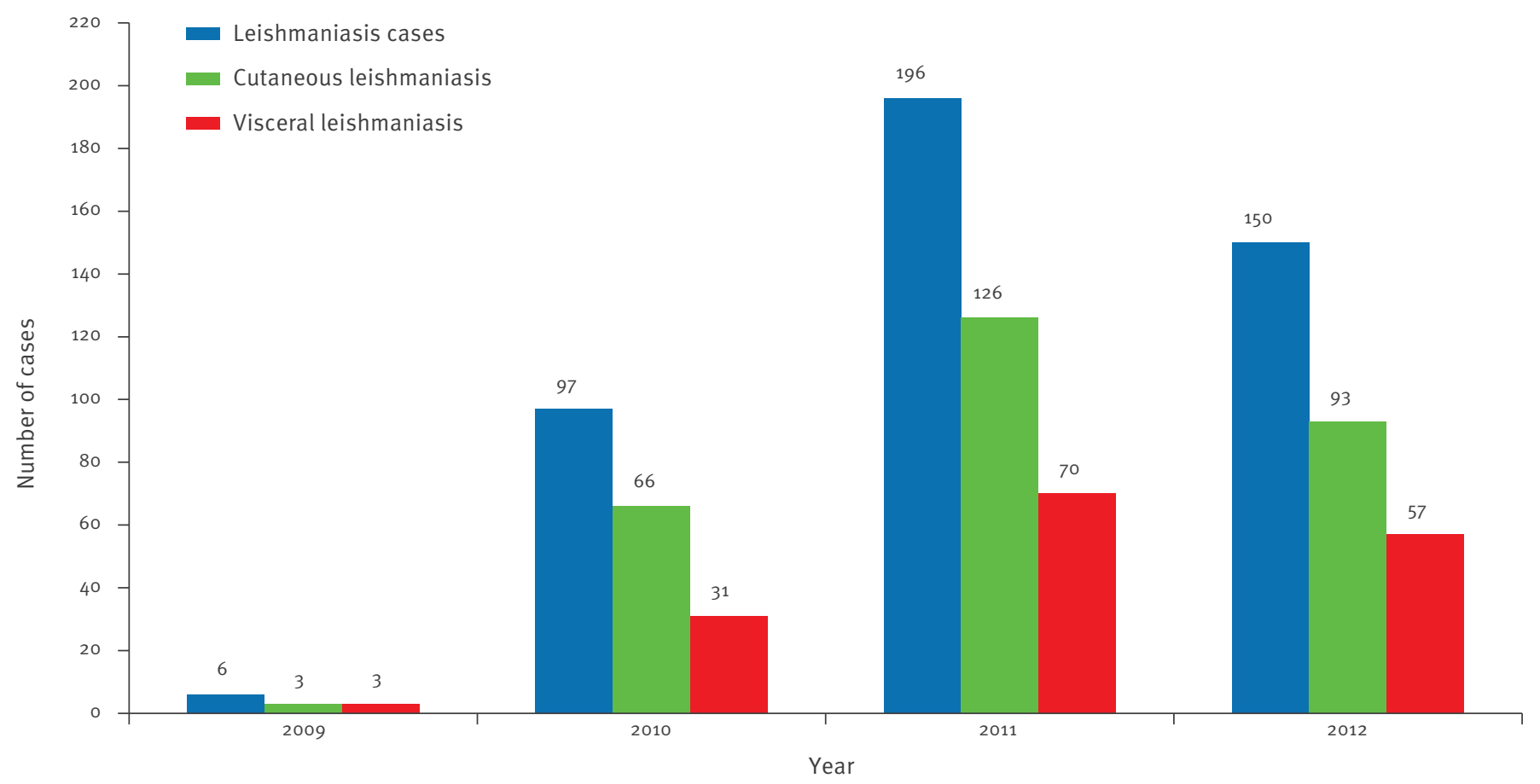

Old World countries were diagnosed, indicative of the intense circulation of parasites at global level. Most imported cases are CL forms caused by L. tropica or $L$. major, but also by neotropical parasites of the $L$. braziliensis, L. amazonensis or L. guyanensis complexes. Although adaptation of the latter parasites to Old World phlebotomine vectors and reservoir hosts does not seem probable, phlebotomine species susceptible to full development of $L$. tropica (P. sergenti) or L. major ( $P$. papatasi) have been recorded in several southern European countries. Notably, the geographical range of P. sergenti extends to Spain, Portugal and Italy (Sicily), where genetic competence of local sandfly populations for anthroponotic L. tropica transmission has been suggested [26]. Because of the zoonotic nature of $L$. major, the probability of its introduction appears to be low. Nevertheless, hybrid Leishmania from Portugal have been reported, which share genetic traits from $L$. infantum and $L$. major, suggesting that adaptation of novel parasites to southern European vectors may take place in the future [27].

\section{New foci in Spain, Crete and Cyprus}

\section{Spain}

Recently, a new $L$. infantum focus has been described in Spain. Since late 2010, an unusual increase of human leishmaniasis cases ( $V L$ and $C L$ ) has been observed in the south-western Madrid region, mainly in Fuenlabrada $(204,838$ inhabitants) and was considered as an outbreak (Figure 1). The incidence rate in this municipality rose from $2.44 / 100,000$ inhabitants in 2009 to $54.2 / 100,000$ inhabitants in 2013. From July 2009 to December 2012, 449 leishmaniasis cases were diagnosed in Fuenlabrada and three affected neighbouring municipalities, Leganés, Getafe, and Humanes de Madrid, of which 158 (35.3\%) were VL.This was the first reported outbreak of VL and $C L$ of such magnitudein Spain.

From 2005 to 2011 a new periurban green park of around 450 hectares with an irrigation system was established very close to the residence of many of the $\mathrm{VL}$ and $\mathrm{CL}$ cases. This provided abundant food for hares in an area previously used for agriculture, now free of predators and hunters.

A survey revealed a large population of hares (Lepus granatensis) and a small population of rabbits living in this park, therefore the role of hares and rabbits as potential reservoirs of leishmaniasis in this focal area was studied during 2011 and 2012. Seroprevalence for Leishmania, studied during the same period in the same area in 2,070 dogs (by rK39 dipstick), was found to be $1.64 \%$ [28]. In addition, Leishmania was detected using a Leishmania-specific nested PCR (Ln-PCR) amplifying three targets (ITS1, ITS2, and hsp7o) which proved to have $100 \%$ specificity for Leishmania [29]. Original R223 and R333 primers [30] used in this Ln-PCR assay detected Leishmania in four of 55 spleen samples from cats $(7.3 \%)$ and in one of 66 spleen samples from rabbits (1.5\%). However, the most interesting results were found in hares, as 43 of 148 animals studied (29\%) were positive in Ln-PCR on spleen or 
skin samples collected between December 2011 and July 2012. Xenodiagnosis assay, carried out on seven hares (using a $P$. perniciosus colony) revealed four positive animals [3], proving for the first time that sandfly vectors acquire $L$. infantum by feeding on apparently healthy hares. Direct sequencing of the positive ITS1, ITS2, and hsp7o PCR products was performed [31]. Molecular characterisation, based on the ITS1 and ITS2 regions and the $h s p 70$ gene of 30 isolates, 24 from humans and six from hares (six positive sandflies after xenodiagnosis of three hares), were consistent with L. infantum and $100 \%$ identical to the sequence of the $L$. infantum strain isolated in Spain in 1987 from a patient with CL. Between December 2011 and February 2013, about 1,200 hares were captured in the park, representing a high population density of around 265 hares $/ \mathrm{km}^{2}$. A preliminary entomological study was conducted in September and October 2011, before starting the disease control measures, in order to analyse by PCR the blood feeding preferences of sandflies (based on the vertebrate cytochrome $b$ gene), which showed a clear feeding preference for hares [32]. In the same study, the detection of Leishmania in the wild-caught $P$. perniciosus (studied by kDNA-PCR and $\mathrm{cpb} P C R$ ) showed that $58.5 \%$ of flies were positive to $L$. infantum. This was the first evidence that hares can play a role as a reservoir of $L$. infantum in Europe, suggesting the existence of a sylvatic transmission cycle linked to the urban periphery. As noted above, the creation of the park resulted in an increase of hares as the reservoir host and sandfly populations, and thus led to the urbanisation of leishmaniasis. The new VL focus in Fuenlabrada is thus an example of leishmaniasis emergence due to environmental changes induced by man. The role of hares, and other possible sylvatic reservoirs, in the epidemiology of leishmaniasis deserves special attention in endemic sites.

\section{Crete}

In the island of Crete, Greece, CL was so common sixty years ago that it had a local name, 'Chaniotico spyri', meaning 'the skin lesion found in the area of Chania'. Yet, after DDT spraying against malaria vectors during World War II, sandfly populations were drastically reduced $[33,34]$ and Crete remained a latent focus for $C L$ for over 25 years [35]. Recently however, CL due to $L$. tropica has re-emerged and spread to all parts of Crete, with an average of five $C L$ cases per year observed in the last three years. The parasite was isolated from relapsed patients, over 60 years-old, who reported that they had 'Chaniotico spyri' during childhood, as most people in their village at that time [35]. Of the 19 $\mathrm{CL}$ cases known in Crete during the last three years, 15 were over 60 years-old. Possibly age-related changes in the immune system of these patients allowed the parasite to become activated and cause new lesions. Such cases are expected to appear in larger numbers as people infected at childhood get older. Currently, L. infantum and L. tropica are found circulating in the island of Crete, a closed ecosystem of $8,336 \mathrm{~km}^{2}$ and with a population of 601,131 (Greek statistics department
2001). They are involved in zoonotic and anthroponotic cycles, with an increasing number of human cases and a reported mixed infection in a dog. The two prevailing Phlebotomus species in Crete are $P$. neglectus and $P$. similis, the first a proven vector of $L$. infantum and the second a suspected vector of $L$. tropica. However, 10 Phlebotomus species are found in the island [35], and vectorial capacities of most of them have not yet been investigated. These species, like $P$. mascittii, may be able to transmit the local parasites but also other parasite species and/or strains that could be introduced to the island, to humans and other hosts, a situation that may complicate the epidemiology of the disease and its implications for public health in the future.

\section{Cyprus}

L. donovani is anthroponotic, causing VL, CL and postkala-azar dermal leishmaniasis, depending on the geographical area. It is considered more aggressive than $L$. infantum and often does not respond to treatment with first-line drugs. For decades, L. infantum in Cyprus has been causing canine leishmaniasis without causing any human cases [36,37]. CanL was a serious veterinary problem until 1945 [38], but became latent after the mosquito eradication campaign [39] and the vast reduction in dog numbers (from 46,000 to 6,000 ) as a consequence of the successful antiechinococcosis campaign between 1970 and 1975 $[40,41]$. Nevertheless, the reservoir host and vector populations for leishmaniasis gradually increased and CanL re-emerged on the island. In 1996, overall CanL seroprevalence was reported to be $1.7 \%$; by 2006 , it had increased six-fold, reaching $33.3 \%$ in some areas. Nevertheless, only one infantile VL case was reported during this period, in 1987 [42]. The situation is different in the northern part of the island not under effective control of the Government of the Republic of Cyprus, where an increasing number of human $C L$ and $V L$, as well as CanL cases have been reported [43]. Although the population of the two parts of Cyprus has been free to cross the green line since 2003 , leishmaniasis cases were not reported in the southern part until 2006, when three $\mathrm{CL}$ and two VL human cases were diagnosed.

For the typing of the isolates from Cyprus, a K26-PCR assay, which is specific for the $L$. donovani complex and discriminates between $L$. donovani and $L$. infantum [44], was used, together with multilocus enzyme electrophoresis (MLEE), the current reference method for characterising and classifying Leishmania strains [45], as well as microsatellite analysis [46]. All methods incriminated $L$. donovani $\mathrm{MON}-37$ as the responsible strain. These isolates were found to be genetically very closely related to the Turkish $L$. donovani MON-37 and differed from the $L$. donovani MON-37 found in all other countries. This indicates that the parasite may have been introduced to Cyprus recently, probably from mainland Turkey, where human leishmaniasis is widespread, by Turkish immigrants and/or the army following the war in 1974. The fact that this strain was isolated from both human hosts and P. tobbi in Turkey 


\section{FIGURE 2}

Cutaneous leishmaniasis due to Leishmania donovani, Cyprus, 2011

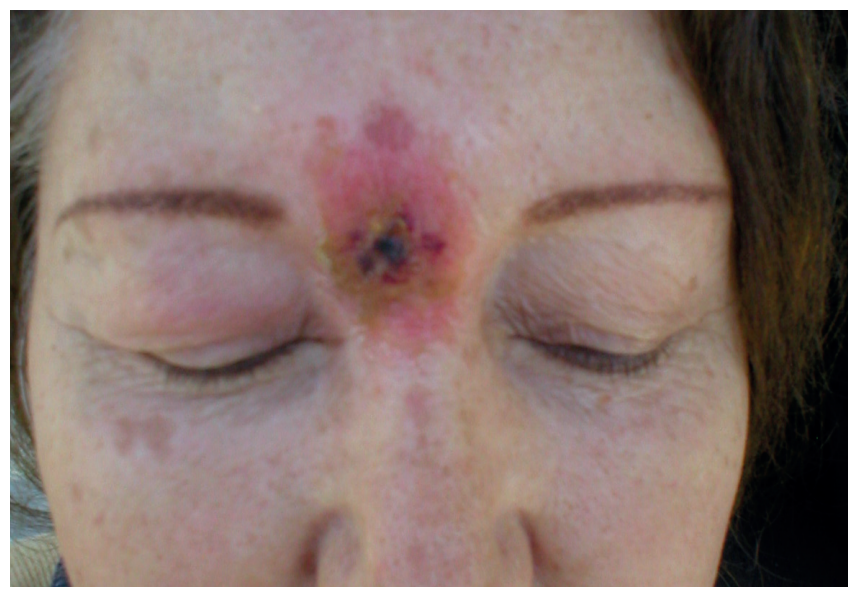

Photograph by Maria Antoniou. The patient agreed for the photograph to be published.

[46], strengthens the hypothesis that this vector may be responsible for the transmission of both Leishmania species in southern Cyprus, where no $P$. neglectus has been recorded so far [37]. However, further studies should investigate the capacity of other species to transmit L. donovani in Cyprus, such as P. galilaeus. Four new human CL cases (Figure 2) and one VL case, caused by L. donovani, have been diagnosed in Cyprus since. L. donovani was also found, as a mixed infection with $L$. infantum, in a dog (one of 20 dogs examined by $K 26-P C R$ ) living in the same district as three $C L$ patients [37].

All evidence indicates that two different transmission cycles are taking place on the island, one of $L$. infantum in dogs and one of $L$. donovani in humans. However, the mixed infection in the dog suggests that the cycles meet, demonstrating that some of the sandfly species found on the island bite both dogs and humans, contrary to what was believed [47]. The question remains: why do humans in the southern part of Cyprus not get infected by L. infantum? A seroepidemiolological study conducted in 600 people in two areas on Cyprus defined as high-risk in a seroepidemiological study conducted in dogs and one area defined as low-risk, did not reveal antibodies against the parasite [37]. However, a larger sample should be studied, to investigate the situation in depth before conclusions can be reached. It is also interesting to note that cases of VL have been reported in tourists visiting Cyprus $[48,49]$ and that no Leishmania and HIV co-infections are known on the island. It is probable that genetic differentiation, in the parasite, the vector or the native population, has taken place, and these possibilities should be investigated to explain the Cyprus paradox [37].

\section{Conclusion}

It is apparent that the epidemiology of the leishmaniases in the Mediterranean basin is changing. Historical foci, silent for several decades, re-emerge and the threat of new strain/species introduction is evident. The new focus in Spain, with hares as reservoirs, clearly shows that hosts, neglected in previous epidemiological considerations, may play a major role in transmission cycles under changing conditions. At the same time, the concept of specific and permissive vectors draws attention to the possibility that a larger number of sandfly species could be incriminated in parasite transmission. Many reports indicate introduction and spread of exotic Leishmania species and zymodeme variants to areas of Europe that are already endemic. In areas where sandfly vectors are well established and circulating the local parasites, such introductions of for example a new L. tropica zymodeme in Crete and L. donovani in Cyprus [36], if able to support and transmit the new invaders, will enhance the possibility of genetic exchange between different species/strains of the parasite. As a result, new hybrids may be generated with different epidemiology, pathogenicity or drug resistance, a situation already shown in Portugal [27].

There is an urgent need to identify both Leishmania species and their vectors in detail. To safeguard public health, targeted control measures must be undertaken by local and European authorities. At the same time it is of vital importance for doctors in human and veterinary medicine to be well informed on the disease symptoms, therapy, and resistance of Leishmania to drugs. Scientific consortiums such as EDENext could prove appropriate platforms to accumulate, coordinate and integrate up-to-date knowledge and assist decision makers in assessing public health problems related to leishmaniases, appropriately.

\section{Acknowledgements}

The authors would like to thank Prof. Luigi Gradoni for advice and continuous support and Maribel Jiménez for reviewing the paper and providing important information. This study was partially funded by EU grant GOCE-2003-010284 EDENext and is catalogued by the EDENext Steering Committee as EDENo56 (http://www.edenext.eu). The contents of this publication are the sole responsibility of the authors and do not necessarily reflect the views of the European Commission. 


\section{References}

1. Alvar J, Vélez ID, Bern C, Herrero M, Desjeux P, Cano J, et al. Leishmaniasis worldwide and global estimates of its incidence. PLOS ONE. 2012;7(5):e35671.

http://dx.doi.org/10.1371/journal.pone.0035671

PMid:22693548 PMCid:PMC3365071

2. Dujardin JC, Campino L, Ca-avate C, Dedet JP, Gradoni L, Soteriadou K, et al. Spread of vector-borne diseases and neglect of leishmaniasis, Europe. Emerg Infect Dis. 2008;14(7):1013-8. http://dx.doi.org/10.3201/eid1407.071589 PMid:18598618 PMCid:PMC 2600355

3. Molina R, Jiménez M, Cruz I, Iriso A, Martín-Martín I, Sevillano 0 , et al. The hare (Lepusgranatensis) as potential sylvatic reservoir of Leishmania infantum in Spain. Vet Parasitol. 2012;190(1-2):268-71.

http://dx.doi.org/10.1016/j.vetpar.2012.05.006 PMid:22677135

4. Alvar J, Aparicio P, Aseffa A, Den Boer M, Canãvate C, Dedet $J P$, et al. The relationship between leishmaniasis and AIDS: the second 10 years. ClinMicrobiol Rev. 2008;21(2):334-59. http://dx.doi.org/10.1128/CMR.00061-07

PMid:18400800 PMCid:PMC 2292576

5. Michel G, Pomares C, Ferrua B, Marty P. Importance of worldwide asymptomatic carriers of Leishmania infantum (L. chagasi) in human. Acta Trop. 2011;119(2-3):69-75. http://dx.doi.org/10.1016/j.actatropica.2011.05.012 PMid:21679680

6. Ready P. Leishmaniasis emergence in Europe. Euro Surveill. 2010;15(10): pii=19505. Available from: http://www. eurosurveillance.org/ViewArticle.aspx?Articleld=19505 PMid:20403308

7. Jacobson R. Leishmaniasis in an era of the conflict in Middle East. Vector Borne Zoonotic Dis. 2011;11(3):247-58. http://dx.doi.org/10.1089/vbz.2010.0068 PMid:20846030

8. Giorgobiani E, Lawyer PG, Babuadze G, Dolidze N, Jochim RC, Tskhvaradze L, et al. Incrimination of Phlebotomus kandelakii and Phlebotomus balcanicus as vectors of Leishmania infantum in Tbilisi, Georgia. PLoSNegl Trop Dis. 2012;6(4):e1609.

9. Volf P, Myskova J. Sand flies and Leishmania: specific versus permissive vectors. Trends Parasitol. 2007;23(3):91-2. http://dx.doi.org/10.1016/j.pt.2006.12.010 PMid:17207663 PMCid:PMC2839922

10. Killick-Kendrick R, Killick-Kendrick M, Tang Y. Anthroponotic cutaneous leishmaniasis in Kabul, Afghanistan: the low susceptibilty of Phlebotomus papatasi to Leishmania tropica. Trans. R. Soc. Trop. Med. Hyg. 1994;88(2):252-3. http://dx.doi.org/10.1016/0035-9203(94)90320-4

11. Pimenta PF, Saraiva EM, Rowton E, Modi GB, Garraway LA, Beverly SM, et al. Evidence that the vectorial competence of phlebotomine sand flies for different species of Leishmania is controlled by structural polymorphisms in the surface lipophosphoglycan. ProcNatlAcadSci U S A. 1994;91(19):9155-9. http://dx.doi.org/10.1073/pnas.91.19.9155 PMid:8090785 PMCid:PMC44766

12. Kamhawi S, Modi GB, Pimenta PF, Rowton E, Sacks DL. The vectorial competence of Phlebotomus sergenti is specific for Leishmania tropica and is controlled by species-specific lipophosphoglycan-mediated midgut attachment. Parasitology. 2000;121(Pt 1):25-33.

http://dx.doi.org/10.1017/So031182099006125

PMid:11085222

13. Jecna L, Dostalova A, Wilson R, Seblova V, Chang KP, Bates $P A$, et al. The role of surface glycoconjugates in Leishmania midgut attachment examined by competitive binding assays and experimental development in sand flies.Parasitology. 2013;140(8):1026-3

http://dx.doi.org/10.1017/So031182013000358

PMid:23611086

14. Svobodova M, Votypka J, Peckova J, Dvorak V, Nasseredin A, Baneth G, et al. Distinct transmission cycles of Leishmania tropica in 2 adjacent foci, Northern Israel. Emerg Infect Dis. 2006;12(12):1860-8. http://dx.doi.org/10.3201/eid1212.060497 PMid:17326936 PMCid:PMC3291354

15. Myskova J, Svobodova M, Beverly SM, Volf P. A lipophosphoglycan-independent development of Leishmania in permissive sand flies. Microbes Infect. 2007;9(3):317-24. http://dx.doi.org/10.1016/j.micinf.2006.12.010 PMid:17307009 PMCid:PMC2839925

16. Svarovska A, Ant T, Seblova V, Jecna L, Beverly S, Volf P. Leishmania major glycosylation mutants require phosphoglycans (lpg2-) but not lipophosphoglycan (lpg1-) for survival in permissive sand fly vectors. PLoSNegl Trop Dis. 2010;4(1):e580. http://dx.doi.org/10.1371/journal.pntd.0000580 PMid:20084096 PMCid:PMC2797086

17. Maroli M, Rossi L, Baldelli R, Capelli G, Ferroglio E, Genchi $C$, et al. The northward spread of leishmaniasis in Italy: evidence from retrospective and ongoing studies on the canine reservoir and phlebotomine vectors. Trop Med Int Health. 2008;13(2):256-64.

http://dx.doi.org/10.1111/j.1365-3156.2007.01998.x

PMid:18304273

18. Dereure J, Vanwambeke SO, Malé P, Martinez S, Pratlong $F$, Balard Y, et al. The potential effects of global warming on changes in canine leishmaniasis in a focus outside the classical area of the disease in Southern France. Vector Borne Zoonotic Dis. 2009;9(6):687-94. http://dx.doi.org/10.1089/vbz.2008.0126 PMid:19271999

19. Gálvez R, Descalzo MA, Guerrero I, Miró G, Molina R. Mapping the current distribution and predicted spread of the leishmaniosis sand fly vector in the Madrid region (Spain) based on environmental variables and expected climate change. Vector Borne Zoonotic Dis. 2011;11(7):799-806. http://dx.doi.org/10.1089/vbz.2010.0109 PMid:21417927

20. Naucke TJ, Menn B, Massberg D, Lorentz S. Sandflies and leishmaniasis in Germany. Parasitol Res. 2008;103(Suppl1):S65-8.

http://dx.doi.org/10.1007/s00436-008-1052-y PMid:19030887

21. Gramiccia M, Gradoni L. The Leishmaniases of Southern Europe. In: Takken W, Knols B, editors. Emerging pests and vector-borne diseases in Europe, Ecology and control of vectorborne diseases, Wageningen: Academic Publishers; 2007. p.75-95.

22. Quinnell RJ, Courtenay O. Transmission, reservoir hosts and control of zoonotic visceral leishmaniasis. Parasitology. 2009;136(14):1915-34. http://dx.doi.org/10.1017/So031182009991156 PMid:19835643

23. Jaouadi K, Haouas N, Chaara D, Gorcii M, Chargui N, Augot D, et al. First detection of Leishmania killicki (Kinetoplastida, Trypanosomatidae) in Ctenodactylusgundi (Rodentia, Ctenodactylidae), a possible reservoir of human cutaneous leishmaniasis in Tunisia.Parasit Vectors. 2011;4:159. http://dx.doi.org/10.1186/1756-3305-4-159 PMid:21834996 PMCid:PMC3162927

24. Martín-Sánchez J, Morales-Yuste M, Acedo-Sánchez C, Barón S, Díaz V, Morillas-Márquez F. Canine leishmaniasis in southeastern Spain. Emerg Infect Dis. 2009;15(5):795-8. http://dx.doi.org/10.3201/eid1505.080969 PMid:19402973 PMCid:PMC2687031

25. Ballart C, Alcover MM, Portús M, Gállego M. Is leishmaniasis widespread in Spain? First data on canine leishmaniasis in the province of Lleida, Catalonia, northeast Spain.Trans R Soc Trop Med Hyg. 2012;106(2):134-6. http://dx.doi.org/10.1016/j.trstmh.2011.11.001 PMid:22137192

26. Depaquit J, Ferté H, Léger N, Lefranc F, Alves-Pires C, Hanafi H, et al. ITS 2 sequences heterogeneity in Phlebotomus sergenti and Phlebotomus similis (Diptera, Psychodidae): possible consequences in their ability to transmit Leishmania tropica. Int J Parasitol. 2002;32(9):1123-31. http://dx.doi.org/10.1016/S0020-7519(02)00088-7

27. Volf P, Benkova I, Myskova J, Sadlova J, Campino L, Ravel C. Increased transmission potential of Leishmania major/ Leishmania infantum hybrids. Int J Parasitol. 2007;37(6):58993. http://dx.doi.org/10.1016/j.ijpara.2007.02.002 PMid:17376453 PMCid:PMC2839924

28. Vilas F, Carpintero J, Sevilla S, Martínez A, OrdobásGavín M, Bernal J, et al. Brote de leishmaniasis en la zonasuroeste de la Comunidad de Madrid. Medidas de investigación y control medioambiental.[Leishmaniasis outbreak in the south-western area of the Community of Madrid.Investigation measures and environmental control]. Prof Vet. 2012;17(79):6-15. Spanish.

29. Cruz I, Ca-avate C, Rubio JM, Morales MA, Chicharro C, Laguna $\mathrm{F}$, et al. A nested polymerase chain reaction ( $L n-P C R)$ for diagnosing and monitoring Leishmania infantum infection in co-infected patients with human immunodeficiency virus.Trans R Soc Trop Med Hyg. 2002;96(Suppl.1):S185-9. http://dx.doi.org/10.1016/So035-9203(02)90074-X

30. van Eys GJ, Schoone GJ, Kroon NC, Ebeling SB. Sequence analysis of small subunit ribosomal RNA genes and its use for detection and identification of Leishmania parasites. MolBiochemParasitol. 1992;51(1):133-42. http://dx.doi.org/10.1016/0166-6851(92)90208-2

31. Fraga J, Montalvo AM, De Doncker S, Dujardin JC, Van der Auwera G. Phylogeny of Leishmania species based on the 
heat-shock protein 70 gene. Infec Genet Evol. 2010;10(2):238-

http://dx.doi.org/10.1016/j.meegid.2009.11.007

PMid:19913110

32. Jiménez M, González E, Iriso A, Marco E, Alegret A, Fúster F, et al. Detection of Leishmania infantum and identification of blood meals in Phlebotomus perniciosus from a focus of human leishmaniasis in Madrid, Spain. Parasitol Res. 2013;112(7):2453-9. http://dx.doi.org/10.1007/s00436-0133406-3 PMid:23535889

33. Hertig, M. Phlebotomus and residual DDT in Greece and Italy. Am J Trop Med Hyg. 1949;29(5):773-809. PMid:18141397

34. Hadjinicolaou J. Present status of Phlebotomus in certain areas of Greece. Bull World Health Organ. 1958;19(6):967-79. PMid:20604045 PMCid:PMC2537816

35. Christodoulou V, Antoniou M, Ntais P, Messaritakis I, Ivović $\mathrm{V}$, Dedet JP, et al. Re-emergence of visceral and cutaneous leishmaniasis in the Greek island of Crete. Vector Borne Zoonotic Dis 2012;12(3):214-22.

http://dx.doi.org/10.1089/vbz.2011.0004 PMid:22217163 PMCid:PMC3300062

36. Antoniou M, Haralambous C, Mazeris A, Pratlong F, Dedet JP, Soteriadou K. Leishmania donovani leishmaniasis in Cyprus. Lancet Infect Dis. 2008;8(1):6-7. http://dx.doi.org/10.1016/S1473-3099(07)70297-9

37. Mazeris A, Soteriadou K, Dedet JP, Haralambous C, Tsatsaris A, Moschandreas J, et al. Leishmaniases and the Cyprus paradox. Am J Trop Med Hyg. 2010;82(3):441-8.

http://dx.doi.org/10.4269/ajtmh.2010.09-0282 PMid:20207870 PMCid:PMC2829906

38. Deplazes P, Grimm F, Papaprodromou M, Cavaliero T, Gramiccia $M$, et al. Canine leishmaniosis in Cyprus due to Leishmania infantum MON 1. Acta Trop. 1998;7(2):169-78. http://dx.doi.org/10.1016/So001-706X(98)00064-3

39. Tesh RB, Papaevangelou G. Effect of Insectiside spraying for Malaria Control on the incidence of sandfly fever in Athens, Greece. Am J Trop Med Hyg. 1977;26(1):163-6. PMid:190909

40. Polydorou K. A short history of echinococcosis control in Cyprus. Hist Med Vet. 1984;9(3):61-4. PMid:11621074

41. Economides P. Control of Zoonoses in Cyprus. Rev Sci Tech. 2000;19(3):725-34. PMid:11107615

42. Minter DM, Eitrem UR. Sandflies and disease in Cyprus: $194^{-}$ 1985. In Hart D.T. (Ed) Leishmaniasis: The current status and new strategies for control. Vol 3. NATO ASI series: Series A: Life sciences. New York: Plenum Press; 1989. P.207-16.

43. Howard MK, Ogunkolade W, Bryceson AD, Davidson RN, Moody AH, Miles MA. A DNA probe for human visceral leishmaniasis. Trans R Soc Trop Med Hyg. 1992;86(1):35-6. http://dx.doi.org/10.1016/0035-9203(92)90430-K

44. Haralambous C, Antoniou M, Pratlong F, Dedet JP, Soteriadou K. Development of a molecular assay specific for the Leishmania donovani complex that discriminates L. donovani/ Leishmania infantum zymodemes: a useful tool for typing MON-1. DiagnMicrobiol Infect Dis. 2008;60(1):33-42. http://dx.doi.org/10.1016/j.diagmicrobio.2007.07.019 PMid:17889482

45. Rioux JA, Lanotte G, Serres E, Pratlong F, Bastien P, Perieres J. Taxonomy of Leishmania. Use of isoenzymes.Suggestions for a new classification. Ann Parasitol Hum Comp. 1990;65(3):111-25. PMid:2080829

46. Gouzelou E, Haralambous C, Amro A, Mentis A, Pratlong F, Dedet JP, et al. Multilocus microsatellite typing (MLMT) of strains from Turkey and Cyprus reveals a novel monophyletic $L$. donovani sensulato group. PLoSNegl Trop Dis. 2012;6(2):e1507.

47. Leger N, Depaquit J, Ferte H, Rioux JA, Gantier JC, Gramiccia M, et al. [Phlebotominesandflies (Diptera-Psychodidae) of the isle of Cyprus. II--Isolation and typing of Leishmania (Leishmania infantum) Nicolle, 1908 (zymodeme MON-1) from Phlebotomus (Larroussius) tobbi Adler and Theodor, 1930].Parasite. 2000;7(2):143-6. French. PMid:10887662

48. Valkoun A, Nádvorník V, Kostrhun L. [A case of visceral leishmaniasis imported from the Mediterranean]. CasLekCesk. 1985;124(51):1582-5. Czech. PMid:4084964

49. Wheatley T, Sacks S, Flemans RJ, Rubenstein D. Visceral leishmaniasis: a rare imported disease. J Infect. 1983;7(2):166-7. http://dx.doi.org/10.1016/S0163-4453(83)90716-8 